\title{
Fracture Liaison Service to Reduce Postoperative Complications and Improve the Activity of Patients With Hip Fracture: A 24-month Follow-up Survey
}

Norio Imai ( $\square$ imainorio2001@yahoo.co.jp )

Department of Orthopedic Surgery, Niigata Prefectural Shibata Hospital, Shibata, Japan 2Division of Comprehensive Musculoskeletal Medicine, Niigata University Graduate School of Medical and Dental

Sciences, Niigata, Japan

\section{Naoto Endo}

Niigata University Graduate School of Medical and Dental Sciences

\section{Ken Suda}

Niigata Prefectural Shibata Hospital

\section{Hayato Suzuki}

Niigata University Graduate School of Medical and Dental Sciences

\section{Research article}

Keywords: complications, fracture liaison service, hip fracture, surgery, mortality

Posted Date: August 31st, 2020

DOl: https://doi.org/10.21203/rs.3.rs-58742/v1

License: (1) This work is licensed under a Creative Commons Attribution 4.0 International License. Read Full License 


\section{Abstract}

Background: Many models of fracture liaison services (FLS) following hip fracture have been introduced in the United Kingdom and Japan, resulting in a reduction in medical complications and secondary fractures. This study investigated improvements in time to surgery, daily activity, and the rate of medical complications and secondary hip fractures following the introduction of FLS.

Methods: Patients who were over 50 years old and experienced fragility hip fractures, including femoral neck and trochanteric fractures, between January 1, 2015 and December 31, 2017, were enrolled in the study. We divided patients into a control group without FLS (94 patients; mean age: 83.8 years; 21 men and 73 women) and an FLS group (373 patients; mean age: 83.3 years; 69 men and 304 women).

Results: The time from injury to surgery decreased significantly from 2.42 days to 1.83 days following the introduction of FLS $(p=0.003)$. The proportion of patients who were able to undergo surgery within 36 hours of injury also increased significantly in the FLS group $(p=0.014)$. In the FLS group, a significant decrease was observed in the total number of cases with complications, including cardiovascular disease, pulmonary disease, and cerebrovascular disease, after admission $(p=0.009,0.010,0.043$, respectively). Significantly more patients with a Barthel index (BI) of $\geq 80$ were observed in the FLS group at 6 months, 12 months, and 24 months following injury ( $p=0.046,0.018$, and 0.048 , respectively). Multiple logistic regression analysis revealed that $\mathrm{BI}$ at the time of injury, surgery within 36 hours of injury, and postoperative complications were associated with death within 12 or 24 months after the injury.

Conclusions: Our results indicate that FLS contributed to earlier recovery and rehabilitation following surgery, and accelerated rehabilitation of medical complications following admission. Our FLS is expected to improve patient activity and decrease secondary hip fracture in patients who have undergone hip surgery.

Trial registration: University Hospital Medical Information Clinical Trials Registry, UMIN000041206. Registered $24^{\text {th }}$ July 2020, https://upload.umin.ac.jp/cgi-in/ctr/ctr_view_reg.cgi?recptno=R000047054

\section{Background}

In Japan, the number of fragility hip fractures is increasing accordingly with the continuously growing elderly population [1]. Orimo et al. reported that the estimated number of patients with new hip fractures was 148,100 in 2007 and 175,7000 in 2012, representing a 20\% increase over 5 years [1]. Our previous study indicated that the average age of patients with hip fracture in the Niigata Prefecture, Japan was 81.4 years in men and 84.9 years in women, and that $80 \%$ of the patients had more than one comorbidity at the time of their fracture in 2015 [2]. Furthermore, $25 \%$ of patients with hip fracture developed medical complications following hospitalization [3]; these are known to delay rehabilitation progress, decrease patient activity, and cause the patient to be bedridden and/or die prematurely. Therefore, a comprehensive treatment of the fracture is necessary. 
Many models of fracture liaison services (FLS) that have been introduced in the United Kingdom [4-9] and Japan [10] have reduced the rate of medical complications and secondary fracture and improved the cost-effectiveness of the treatment [11-13].

In our institution, we introduced FLS based on the methods implemented in Toyama, Japan [10]. As data on hip fracture outcomes following FLS introduction are scarce in Japan, our study investigated improvements in time to surgery, daily activity, and the rate of medical complications after admission and secondary hip fractures following the introduction of FLS.

\section{Methods}

\section{Participants}

This study was conducted in accordance with the principles of the Declaration of Helsinki (1964) and was approved by the institutional review board of Niigata Prefectural Shibata Hospital, Shibata City, Niigata Prefecture, Japan (approval no. 167). The need for written informed consent for study participation was waived by the approving authority due to the retrospective cohort design of this study. Only the corresponding author and co-authors had administrative permissions with regard to this research. Licenses to access the data were acquired by the authors from Niigata Prefectural Shibata Hospital to use data for this research.

Patients who had a fragility hip fracture, including a femoral neck or trochanteric fracture, between January 1, 2015 and December 31, 2017 and were older than 50 years at the time of injury were enrolled retrospectively in the study. We excluded patients with pathological and periprosthetic fractures, highenergy injuries (e.g., those due to traffic accidents), and falls from heights. We assigned the remaining patients to two groups: patients who were injured between January 1 and June 30, 2015 who had not received FLS (control group; $n=122$ ), and those who were injured between July 1, 2015, and December 31, 2017 and received FLS (FLS group; $n=507$ ). Additionally, we excluded patients who were lost to follow-up at less than 3 months after the injury. The final analysis included 94 and 373 patients in the control and FLS groups, respectively (Fig. 1).

\section{FLS outline}

To reduce the burden of consultation with internists, we based the consultation criteria on a report by Shigemoto et al. [10] as well as information provided in Table 1. As recommended by several hip fracture management guidelines, we consulted with various specialists regarding early surgery (36 hours after the injury) based on the patient status, as shown in Table 1 [14-17]. A dedicated nephrologist from the Japan Osteoporosis Society ensured cooperation between orthopedic surgeons and internists. Furthermore, an anesthesiologist arranged surgery as early as possible if the patient's condition was amenable to surgery. 
To prevent secondary fracture, we introduced anti-osteoporosis outpatient medications, such as bisphosphonate, at 1-3 months after the injury occurred.

Table 1

Consultation criteria by internist subspecialty

\begin{tabular}{|ll|}
\hline Subspecialty & Target disease or physical condition \\
\hline Cardiologist & $\begin{array}{l}\text { History of cardiovascular disease } \\
\text { Abnormal findings on electrocardiogram at admission }\end{array}$ \\
\hline Pulmonologist & $\begin{array}{l}\text { History of bronchial asthma, home oxygen therapy } \\
\text { Arterial oxygen saturation less than } 90 \% \text { in room air } \\
\text { Pneumonia at admission }\end{array}$ \\
\hline Neurologist & $\begin{array}{l}\text { Patients on hemodialysis } \\
\text { Chronic kidney disease with eGFR less than } 40 \mathrm{~mL} / \mathrm{min}\end{array}$ \\
\hline Endocrinologist & $\begin{array}{l}\text { Casual blood glucose greater than } 200 \mathrm{ng} / \mathrm{dL} \\
\text { infarction }\end{array}$ \\
\hline Gastroenterologist & History of diabetes mellitus, including type 1 \\
\hline
\end{tabular}

\section{Survey components}

Patient information, including age (years), sex, days from injury to surgery, and the rate at which surgery occurred within 36 hours of injury, number and proportion of patients who had undergone surgery, and average length of hospital stay (days), was collected using surveys. Additionally, data on comorbidities at the time of surgery (as classified in our previous study [3]: hypertension, cardiovascular disease, pulmonary disease, renal disease, diabetes, cerebrovascular disease, and digestive disease), complications following admission, including worsening of a comorbidity, and hip fracture on the opposite side within 12 and 24 months after the first hip fracture was also collected.

Further, we examined the rate of anti-osteoporosis medication compliance, daily activity as evaluated by the Barthel index (BI), and the rate of patients whose $\mathrm{BI}$ was $\geq 80$, i.e., considered independent [18]. The aforementioned parameters were evaluated at admission and at 3, 6, 12, and 24 months after the injury. Moreover, mortality was examined within 1, 12, and 24 months after the injury. When evaluating antiosteoporosis medication compliance and daily activities, deceased patients and those lost to follow-up were excluded from the analyses at 3, 6, 12, and 24 months (Fig. 1). The data were obtained from medical records via telephone calls or via surveys mailed to patients or their families by a specialized liaison nurse certified by the Japan Osteoporosis Society.

\section{Statistical analysis}


We used SPSS statistical software (version 24; SPSS, Inc., Chicago, IL) to analyze data. To assess the normality of distribution of continuous variables, we used the Kolmogorov-Smirnov test. The Fisher's exact test was employed to compare qualitative data, e.g., the number of men and women. The unpaired Student's $t$-test was used to analyze quantitative data, such as those for age. To determine mortality, the Kaplan-Meier analysis and log-rank test were conducted. We also performed a post-hoc analysis to evaluate statistical power (type II [ $\beta$ ] error). We defined the effect size (d) as 0.5 and type I (a) error as 0.05 for the $t$-test, and the effect size (d) as 0.3 and type I (a) error as 0.05 in the Fisher's exact test. Moreover, we used multiple logistic analysis to determine which of the following factors contributed to postoperative complications: age, sex, FLS intervention, BI at injury, and surgery within 36 hours of injury. Furthermore, using multiple logistic regression analysis, we evaluated the contribution to death of the following variables, within 12 and 24 months after injury: age, sex, FLS intervention, BI at injury, surgery within 36 hours of injury, and occurrence of postoperative complications. A two-tailed $p$-value of $<0.05$ was considered statistically significant.

\section{Results}

Detailed participant characteristics are described in Table 2. The number of days between injury and surgery decreased significantly from 2.42 days to 1.83 days after FLS introduction ( $p=0.003$; Table 2$)$. Moreover, the proportion of patients who were able to undergo surgery within 36 hours of injury increased significantly in the FLS group ( $p=0.014$; Table 2$)$. The hospital length of stay was similar in both groups, while the proportion of patients who underwent surgery after the injury also increased significantly from 86.2-93.8\% ( $p=0.018$; Table 2). 
Table 2

Characteristics of the study participants

\begin{tabular}{|c|c|c|c|}
\hline & Control group & FLS group & $\begin{array}{l}\mathrm{p}- \\
\text { value }\end{array}$ \\
\hline Patients & 94 & 373 & \\
\hline Age (years) & $83.3 \pm 8.8$ & $83.3 \pm 10.3$ & $0.950 *$ \\
\hline Sex (Men/women) & $\begin{array}{l}21 / 73 \text { (women: } \\
77.7 \% \text { ) }\end{array}$ & $\begin{array}{l}\text { 69/304 (women: } \\
81.6 \% \text { ) }\end{array}$ & $0.384^{\dagger}$ \\
\hline Delay in surgery (days from injury) & $2.42 \pm 2.19$ & $1.83 \pm 1.45$ & $0.003^{*}$ \\
\hline Cases that underwent any surgery & $81(86.2 \%)$ & $350(93.8 \%)$ & $0.018^{\dagger}$ \\
\hline $\begin{array}{l}\text { Surgery performed within } 36 \text { hours of } \\
\text { injury }\end{array}$ & $52(55.3 \%)$ & $259(69.4 \%)$ & $0.014^{\dagger}$ \\
\hline Hospital stay (days) & $22.6 \pm 10.7$ & $20.8 \pm 8.2$ & $0.346^{\star}$ \\
\hline \multicolumn{4}{|l|}{ Comorbidity at injury } \\
\hline$n(\%)$ & $82(87.2 \%)$ & $325(87.1 \%)$ & $0.871^{\dagger}$ \\
\hline Hypertension & $37(39.3 \%)$ & $193(51.7 \%)$ & $0.038^{\dagger}$ \\
\hline Cardiovascular disease & $25(26.6 \%)$ & $95(25.4 \%)$ & $0.895^{\dagger}$ \\
\hline Pulmonary disease & $6(6.4 \%)$ & $31(8.3 \%)$ & $0.671^{\dagger}$ \\
\hline Renal disease & $9(9.6 \%)$ & $42(11.3 \%)$ & $0.715^{\dagger}$ \\
\hline Diabetes & $8(8.5 \%)$ & $54(14.5 \%)$ & $0.172^{\dagger}$ \\
\hline Cerebrovascular disease & $18(19.1 \%)$ & $83(22.3 \%)$ & $0.577^{\dagger}$ \\
\hline Digestive disease & $32(34.0 \%)$ & $124(33.2 \%)$ & $0.902^{\dagger}$ \\
\hline \multicolumn{4}{|l|}{ Complications after admission, } \\
\hline$n(\%)$ & $22(23.4 \%)$ & $46(12.3 \%)$ & $0.009^{\dagger}$ \\
\hline Cardiovascular disease & $8(8.5 \%)$ & $9(2.4 \%)$ & $0.010^{\dagger}$ \\
\hline Pulmonary disease & $10(10.6 \%)$ & $17(4.6 \%)$ & $0.043^{\dagger}$ \\
\hline Renal disease & $4(4.3 \%)$ & $7(1.9 \%)$ & $0.244^{\dagger}$ \\
\hline Cerebrovascular disease & $5(5.3 \%)$ & $6(1.6 \%)$ & $0.049^{\dagger}$ \\
\hline
\end{tabular}

\#: including duplicate cases; *: Student's $t$-test; ${ }^{\dagger}$ : Fisher's exact test 


\begin{tabular}{|lccc|}
\hline & Control group & FLS group & $\begin{array}{c}\text { p- } \\
\text { value }\end{array}$ \\
\hline Digestive disease & $2(2.1 \%)$ & $6(1.6 \%)$ & $0.665^{\dagger}$ \\
\hline \#: including duplicate cases; *: Student's $t$-test; ${ }^{\dagger}$ : Fisher's exact test & & \\
\hline
\end{tabular}

A significant decrease was observed in the total number of cases who developed complications following admission $(p=0.009)$ and in the number of cases with cardiovascular $(p=0.010)$, pulmonary $(p=0.043)$, and cerebrovascular $(p=0.049)$ disease in the FLS group. The rate of comorbidities at the time of the injury was similar in both groups (Table 2 ).

The rate of anti-osteoporosis medication compliance was significantly higher in the FLS group than in the control group at 3, 6, 12, and 24 months after injury (Table 3). Daily activities of patients were similar at all examined periods. However, the proportion of patients with a $\mathrm{BI}$ of $\geq 80$ was significantly higher in the FLS group at 6,12 , and 24 months after injury $(p=0.046,0018$, and 0.048 , respectively; Table 3$)$. Although the mortality rate was similar in both groups, it was slightly lower in the FLS group throughout the study period (Fig. 2). Based on multiple logistic regression analysis, FLS intervention (odds ratio: $0.372, p=0.004$ ), and $\mathrm{BI}$ at the time of injury (odds ratio: $0.978, p=0.004$ ) significantly affected the occurrence of postoperative complications. $\mathrm{Bl}$ at the time of injury (odds ratio: 0.975 and $0.977 ; p=0.002$ and 0.001 ), surgery within 36 hours of injury (odds ratio: 0.406 and $0.453 ; p=0.013$ and 0.004 ), and postoperative complications (odds ratio: 4.396 and 2.389; $p=0.001$ and 0.021) were factors that contributed significantly to patient death within 12 or 24 months. The post-hoc analysis revealed that the power of the $t$-test and the Fisher's exact test were 0.941 and 0.999 , respectively. 
Table 3

पComparison of outcomes following injury

\begin{tabular}{|c|c|c|c|}
\hline & $\begin{array}{l}\text { Control } \\
\text { group }\end{array}$ & FLS group & p-value \\
\hline \multicolumn{4}{|l|}{ Rate of medication for osteoporosis } \\
\hline At injury & $7 / 94(7.2 \%)$ & $31 / 373(8.3 \%)$ & $0.784^{\dagger}$ \\
\hline 3 months after injury & $\begin{array}{l}17 / 89 \\
(19.1 \%)\end{array}$ & $\begin{array}{l}168 / 351 \\
(47.8 \%)\end{array}$ & $\begin{array}{l}< \\
0.001^{\dagger}\end{array}$ \\
\hline 6 months after injury & $\begin{array}{l}28 / 82 \\
(34.1 \%)\end{array}$ & $\begin{array}{l}166 / 304 \\
(54.6 \%)\end{array}$ & $0.001^{\dagger}$ \\
\hline 12 months after injury & $\begin{array}{l}23 / 74 \\
(31.1 \%)\end{array}$ & $\begin{array}{l}160 / 274 \\
(58.4 \%)\end{array}$ & $\begin{array}{l}< \\
0.001^{\dagger}\end{array}$ \\
\hline 24 months after injury & $\begin{array}{l}17 / 63 \\
(27.0 \%)\end{array}$ & $\begin{array}{l}148 / 243 \\
(60.9 \%)\end{array}$ & $\begin{array}{l}< \\
0.001^{\dagger}\end{array}$ \\
\hline \multicolumn{4}{|l|}{ Barthel index (BI) } \\
\hline At injury & $84.9 \pm 19.1$ & $86.7 \pm 17.7$ & $0.375^{\star}$ \\
\hline $\mathrm{BI} \geq 80$ & $\begin{array}{l}68 / 94 \\
(72.3 \%)\end{array}$ & $\begin{array}{l}265 / 373 \\
(71.0 \%)\end{array}$ & $0.899^{\dagger}$ \\
\hline 3 months after injury & $60.4 \pm 29.5$ & $66.6 \pm 30.2$ & $0.222^{\star}$ \\
\hline $\mathrm{BI} \geq 80$ & $\begin{array}{l}30 / 89 \\
(33.7 \%)\end{array}$ & $\begin{array}{l}152 / 351 \\
(43.3 \%)\end{array}$ & $0.118^{+}$ \\
\hline 6 months after injury & $64.5 \pm 30.2$ & $70.6 \pm 29.5$ & $0.129 *$ \\
\hline $\mathrm{BI} \geq 80$ & $\begin{array}{l}34 / 82 \\
(41.5 \%)\end{array}$ & $\begin{array}{l}165 / 304 \\
(54.3 \%)\end{array}$ & $0.046^{\dagger}$ \\
\hline 12 months after injury & $66.5 \pm 30.7$ & $71.6 \pm 28.8$ & $0.228^{*}$ \\
\hline $\mathrm{BI} \geq 80$ & $\begin{array}{l}31 / 74 \\
(41.9 \%)\end{array}$ & $\begin{array}{l}158 / 274 \\
(57.7 \%)\end{array}$ & $0.018^{\dagger}$ \\
\hline 24 months after injury & $65.3 \pm 32.8$ & $71.9 \pm 28.5$ & $0.190^{\star}$ \\
\hline $\mathrm{BI} \geq 80$ & $\begin{array}{l}27 / 63 \\
(42.9 \%)\end{array}$ & $\begin{array}{l}138 / 243 \\
(56.8 \%)\end{array}$ & $0.048^{\dagger}$ \\
\hline $\begin{array}{l}\text { Opposite-side fracture within } 1 \text { year after first hip } \\
\text { fracture }\end{array}$ & $3 / 74(4.1 \%)$ & $7 / 274(2.5 \%)$ & $0.449^{\dagger}$ \\
\hline $\begin{array}{l}\text { Opposite-side fracture within } 2 \text { years after first hip } \\
\text { fracture }\end{array}$ & $5 / 63(7.9 \%)$ & $12 / 243(4.9 \%)$ & $0.359^{\dagger}$ \\
\hline
\end{tabular}




\section{Discussion}

In this study, we observed that $23.4 \%$ of patients among the control group experienced complications after admission; this rate was similar to the rates reported in previous research $[3,10]$. Contrastingly, complications decreased following admission among the FLS group. Based on the logistic regression analysis, our results can be explained by more prompt surgery and internist intervention for comorbidities at the time of injury, which decreased the occurrence of new complications after admission and prevented existing comorbidities from worsening. Similar results have been observed in previous studies $[10,19-21]$. Moreover, more patients were able to undergo hip surgery after FLS introduction at our hospital, possibly due to cooperation between orthopedic surgeons and internists. Furthermore, the number of complications after admission and before surgery decreased, and cooperation with anesthesiologists was associated with more prompt surgery. In this study, hospital length of stay was similar in both groups. In a meta-analysis of 18 studies by Grigoryan et al., the hospital lengths of stay decreased following FLS intervention [15]. In our hospital, many patients are transferred to the recoveryphase rehabilitation hospital at 2 weeks after admission or surgery; therefore, no difference in the hospital length of stay could be observed between the two groups. With regard to the daily living activities, no significant differences were observed during the study period; however, the BI was approximately 6 points higher in the FLS group at 3-24 months after admission. Moreover, the proportion of patients whose BI was $\geq 80$ was significantly higher in the FLS group at 6,12 , and 24 months after injury. Earlier recovery after rehabilitation, more prompt surgery, as well as a decrease in delaying rehabilitation due to medical complications after admission, may explain this finding. In contrast, no significant differences were observed in terms of the incidence of opposite side hip fractures within 1 year and 2 years from the first hip fracture between the two groups, although the rate was slightly lower in the FLS group. However, the rate of taking anti-osteoporosis medication was higher in the FLS group. Axelsson et al. described that their FLS did not decrease incidence of recurrent hip fracture, although the risk of recurrent incidence of fragility fracture, including hip fracture, was decreased in their Swedish cohort study [22], which reported similar results to ours. This may be because the rate of opposite-side fracture was initially very low. Although slightly lower in the FLS group, the mortality rate was similar in the two groups, consistent with the results to those of Axelsson et al. [22]. Given that the majority of participants were over the age of 80 , the mortality rate for this cohort might be high even without hip fractures; therefore, our FLS may not have a significant effect on mortality.

This study has several limitations. First, the sample size was small, approximately 600 patients. However, the statistical power was sufficient. Second, this study was a retrospective cohort study, which may have affected the interpretation of the results. However, we acquired our data from a robust prospective database that was accurately constructed by trained staff. Third, only approximately $70 \%$ of the patients were carefully followed up. Although our hospital serves patients from a wide area, they are transferred to recovery-phase rehabilitation hospitals closer to their area of residence; consequently, many patients did not visit our institution. Therefore, we attempted to track patients using medical records, telephone calls, and mail; nevertheless, we were unable to monitor several patients. Additional prospective studies examining a large sample are warranted. 


\section{Conclusion}

Following FLS introduction, we observed prompt surgery more frequently in addition to a decrease in the rate of complications following admission, which may improve patient independence in performing daily activities. Therefore, the FLS intervention presented herein is expected to improve patient activity and decrease the rate of secondary hip fractures following hip surgery.

\section{Abbreviations}

$\mathrm{BI}$

Barthel index

FLS

fracture liaison service

\section{Declarations}

Ethics approval and consent to participate: The institutional review board of Niigata Prefectural Shibata Hospital, Shibata City, Niigata Prefecture, Japan approved this study (approval no. 167) and waived the need for informed consent because of the retrospective, cross-sectional study design.

Consent for publication: Not applicable

Availability of data and materials: The datasets used and/or analysed during the current study are available from the corresponding author on reasonable request.

Competing interests: The authors declare that they have no competing interests.

Funding: Not applicable

Authors' contributions: Conceptualization and formulation were performed by NI, HS, and NE. Investigation and data collection were done by all the authors. NI carried out the statistical analysis. The study was performed under the supervision of NE. All authors read and approved the final manuscript.

Acknowledgements: We would like to express our gratitude to Ms. Hidano and Ms. Takai for their devoted assistance. Without their cooperation, this study would not have been possible. We also would like to thank Editage (www.editage.com) for English language editing and Publication Support.

\section{References}

1. Orimo H, Yaegashi $Y$, Hosoi T, Fukushima $Y$, Onoda $T$, Hashimoto $T$, et al. Hip fracture incidence in Japan: Estimates of new patients in 2012 and 25-year trends. Osteoporos Int. 2016;27:1777-84

2. Imai N, Endo N, Shobugawa Y, Ibuchi S, Suzuki H, Miyasaka D, et al. A decrease in the number and incidence of osteoporotic hip fractures among elderly individuals in Niigata, Japan from 2010 to 
2015. J Bone Miner Metab. 2018;26:573-9.

3. Imai N, Endo N, Hoshino T, Suda K, Miyasaka D, Ito T, et al. Mortality after hip fracture with vertebral compression fracture is poor. J Bone Miner Metab. 2016;34:51-

4. McLellan AR, Gallacher SJ, Fraser M, McQuillian C. The fracture liaison service: success of a program for the evaluation and management of patients with osteoporosis fracture. Osteoporos Int. 2003;18:1397-403.

5. Adunsky A, Lerner-Geva L, Blumstein T, Boyko V, Mizrahi E, Arad M. Improved survival of hip fracture patients treated within a comprehensive geriatric hip fracture unit, compared with standard of care treatment. J Am Med Dir Assoc. 2011;12:439-44.

6. Vidan M, Serra JA, Moreno C, Riquelme G, Ortiz J. Efficacy of a comprehensive geriatric intervention in order patients hospitalized for hip fracture: a randomized, controlled trial. J Am Geriatr Soc. 2005;53:1476-82.

7. Gonzalez-Montalvo JI, Alarcon T, Mauleon JL, Gil-Caray E, Gotor P, Martin-Vega A. The orthogeriatric unit for acute patients: a new model of care that improves efficiency in the management of patients with hip fracture. Hip Int. 2010;20:229-35.

8. Friedman SM, Mendelson DA, Bingham KW, Kates SL. Impact of a comanaged Geriatric Fracture Center on short-term hip fracture outcomes. Arch Intern Med. 2009;169:1712-7.

9. Leung AH, Lam TP, Cheung WH, Chan T, Sze PC, Lau T, Leung KS. An orthogeriatric collaborative intervention program for fragility fractures: a retrospective cohort study. J Trauma. 2011;71:1390-4.

10. Shigemoto K, Sawaguchi T, Goshima K, Iwai S, Nakanishi A, Ueoka K. The effect of a multidisciplinary approach on geriatric hip fractures in Japan. J Orthop Sci. 2019;24:280-5.

11. Moriwaki K, Noto S. Economic evaluation of osteoporosis liaison service for secondary fracture prevention in postmenopausal osteoporosis patients with previous hip fracture in Japan. Osteoporos Int. 2017;28:621-32.

12. Yong JH, Masucci L, Hoch JS, Beaton D. Cost-effectiveness of a fracture liaison service-a real-world evaluation after 6 years of service provision. Osteoporos Int. 2016;27:231-40.

13. Cha YH, Ha YC, Lim JY, Kim WS. Introduction of the cost-effectiveness studies of Fracture Liaison Service in other countries. J Bone Metab. 2020;27:79-83.

14. Harty JA, McKenna P, Moloney D, D'Souza L, Masterson E. Anti-platelet agents and surgical delay in elderly patients with hip fractures. J Orthop Surg. 2007;15:270-2.

15. Grigoryan KV, Javedan H, Rudolph JL. Orthogeriatric care models and outcomes in hip fracture patients: a systematic review and meta-analysis. J Orthop Trauma 2014;28:e49-55.

16. National Institute for Health and Clinical Excellence. Hip fracture: management. NICE Clinical Guideline, 124. 2011. http://guidance.nice.org.uk/CG124 Accessed 26 July 2020.

17. Nyholm AM, Gromov K, Palm H, Brix M, Kallemose T, Troelsen A, et al. Time to surgery is associated with thirty-day and ninety-day mortality after proximal femoral fracture: a retrospective observational 
study on prospectively collected data from the Danish fracture database collaborators. J Bone Joint Surg. 2015;97:1333-9.

18. Matzen LE, Jepsen DB, Ryg J, Masud T. Functional level at admission is a predictor of survival in older patients admitted to an acute geriatric unit. BMC Geriatr. 2012;12:32.

19. Grimes JP, Gregory PM, Noveck H, Butler MS, Carson JL. The effects of time-to surgery on mortality and morbidity in patients following hip fracture. Am J Med. 2002;112:702-9.

20. Bergeron E, Lavoie A, Moore L, Bamvita JM, Ratte S, Gravel C, Clas D. Is the delay to surgery for isolated hip fracture predictive of outcome in efficient systems? J Trauma. 2006;60:753-7.

21. Khan SK, Kalra S, Khanna A, Thiruvengada MM, Parker MJ. Timing of surgery for hip fractures: a systematic review of 52 published studies involving 291,413 patients. Injury. 2009;40:692-7.

22. Axelsson KF, Johansson $H$, Lundh $D$, Möller M, Lorentzon M. Association between recurrent fracture risk and implementation of fracture liaison services in four Swedish hospitals: A cohort study. J Bone Miner Res. 2020;35:1216-23.

\section{Figures}


Patients with fragility hip fracture between January 1, 2015, and December 31, $2017(n=699)$

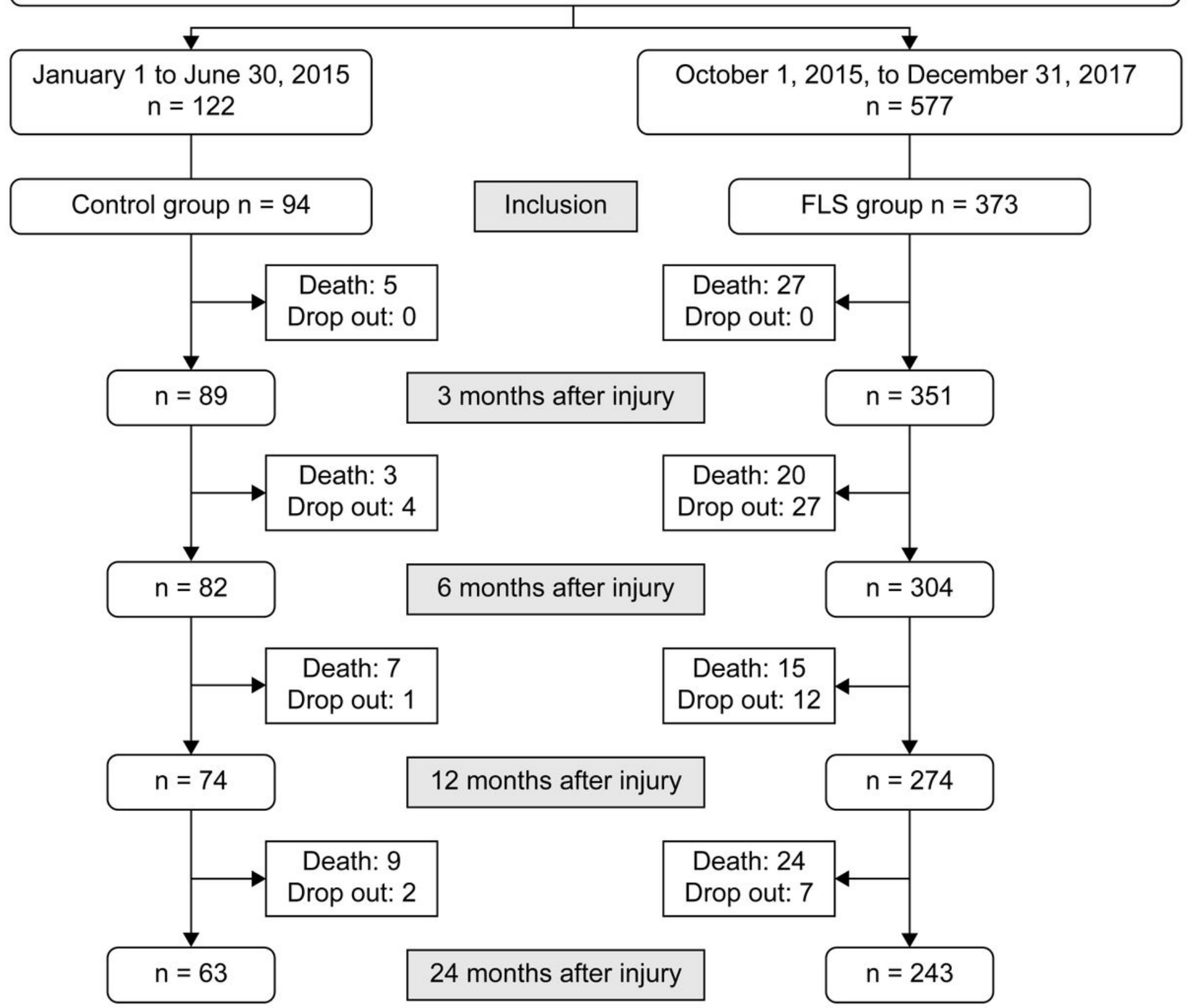

Figure 1

Flow diagram of eligibility criteria. 


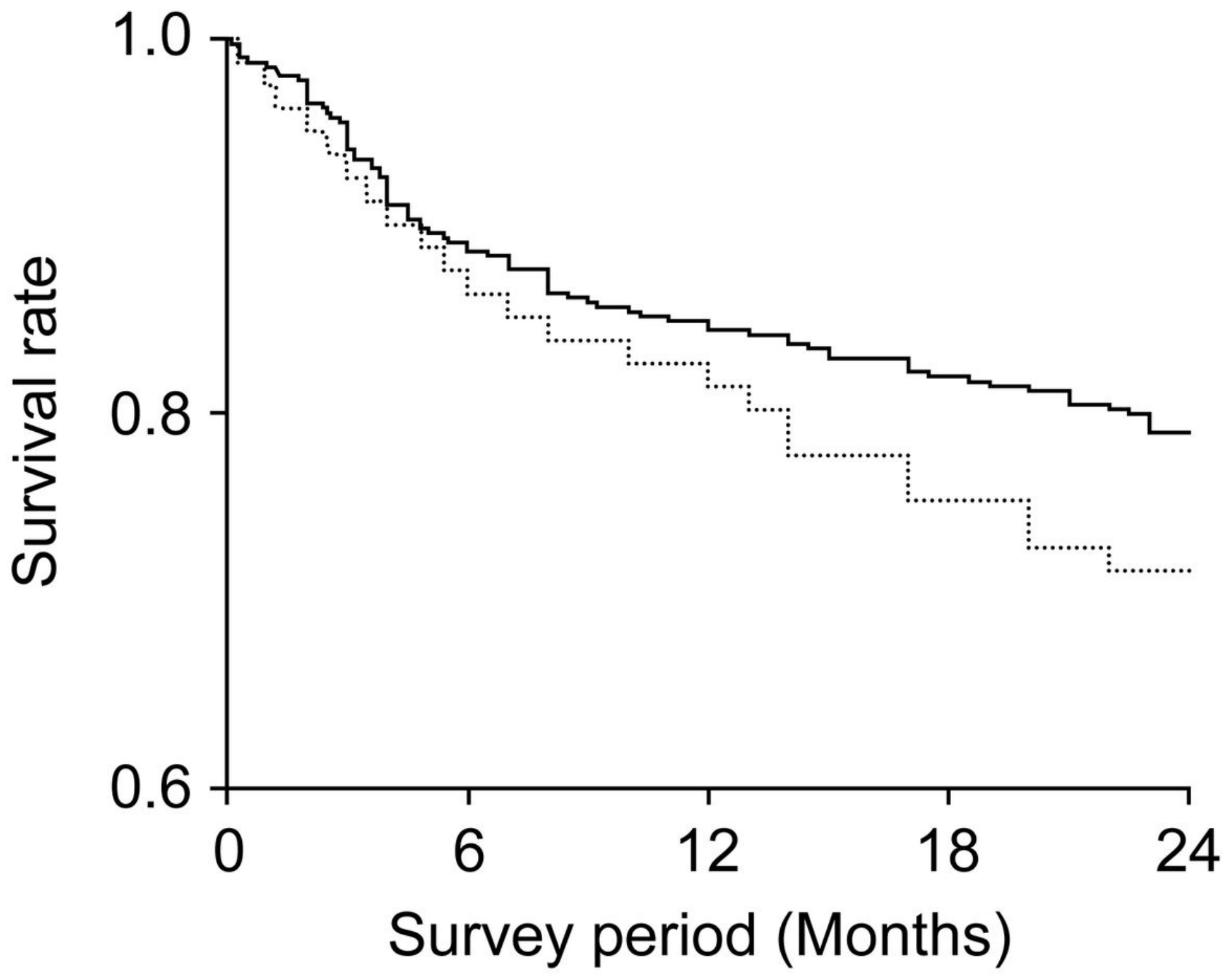

Figure 2

Kaplan-Meier survival estimates. Although significant differences in mortality rates were not observed between the two groups, the mortality rate was slightly lower in the fraction liaison service group. 